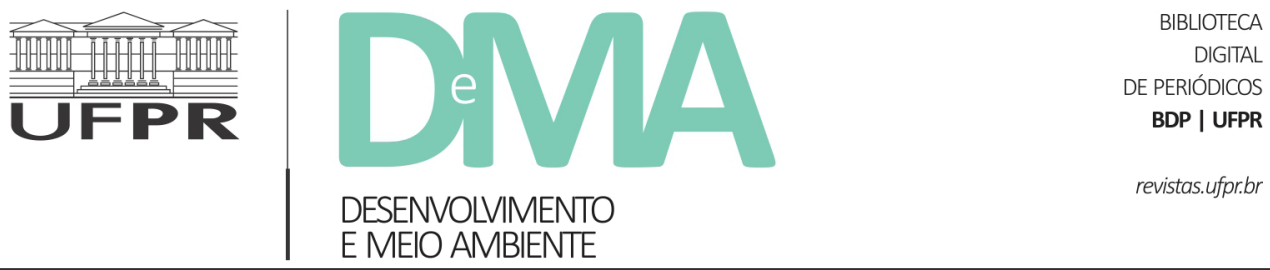

\title{
Análise do impacto da transição da estrutura etária no consumo de energia elétrica domiciliar do Brasil
}

\section{Analysis of the impact of the age structure transition on electricity consumption in Brazilian households}

\author{
Victor Hugo Dias DIÓGENES ${ }^{1}$, Ricardo OJIMA²* \\ ${ }^{1}$ Universidade Federal da Paraíba (UFPB), João Pessoa, PB, Brasil. \\ ${ }^{2}$ Universidade Federal do Rio Grande do Norte (UFRN), Natal, RN, Brasil. \\ *E-mail de contato: ricardo.ojima@gmail.com
}

Artigo recebido em 29 de agosto de 2019, versão final aceita em 11 de agosto de 2020, publicado em 25 de novembro de 2020.

RESUMO: $\quad$ O estudo do consumo na relação entre População e Ambiente (P-A) vem ganhando destaque e notoriedade, já que se vem comprovando que se trata de uma variável que é extremamente correlacionada com a dinâmica demográfica. Dito isso, este trabalho teve como objetivo analisar o consumo de energia elétrica domiciliar per capita por estágios do ciclo de vida do domicílio no Brasil e simular o comportamento do consumo energético considerando as mudanças na estrutura etária domiciliar. A metodologia proposta consistiu em mensurar taxas específicas de consumo por fase do ciclo de vida do domicílio e, por meio de técnicas de padronização direta, verificar o nível de consumo energético caso o Brasil apresentasse outras estruturas etárias em seus domicílios. O banco de dados utilizado foi a Pesquisa de Orçamento Familiares 2008/2009. Quanto aos resultados, eles indicaram que o nível de consumo de energia elétrica domiciliar per capita apresentado pelo Brasil em 2009 diminuiria em 2,6 kWh se o país possuísse a estrutura etária observada em 1970. Como conclusão, a partir dos resultados, tem-se que deve haver um aumento do consumo de energia elétrica quando os domicílios apresentarem uma estrutura por idade do chefe mais envelhecida, ou seja, um maior consumo deve surgir, em parte, devido ao envelhecimento populacional. Portanto, esta pesquisa corrobora com a desmistificação do malthusianismo, cuja ideia principal atribui importância demasiada no volume populacional no debate ambiental em detrimento de outras varáveis demográficas, bem como fortalece a necessidade de se criar e consolidar uma linha de pesquisa sistemática da "demografia do consumo".

Palavras-chave: população-ambiente; consumo; transição demográfica; energia elétrica.

Desenvolv. e Meio Ambiente usa uma Licença Creative Commons - Atribuição-NãoComercial-SemDerivações 4.0 Internacional 
ABSTRACT: The study of consumption in the relationship between Population and Environment (P-E) has been gaining prominence and notoriety since it is being proved that this is a variable that is extremely correlated with demographic dynamics. The objective of this study is to analyze the consumption of household electricity per capita by stages of the household life cycle in Brazil and to simulate the behavior of energy consumption considering changes in the household age structure. The proposed methodology consists of measuring specific consumption rates by the phase of the household's life cycle and, through direct standardization techniques, verifying the level of energy consumption in case Brazil had other age structures in its households. The database used in this research was the 2008/2009 Consumer Expenditure Survey. The results indicate that the level of household electricity consumption per capita presented by Brazil in 2009 would decrease by $2.6 \mathrm{kWh}$ if the country had the age structure observed in 1970. As a conclusion from the results, there will likely be an increase in the consumption of electricity when the households will have a more aged structure, by the age of the head of the household. That means consumption should increase, in part, due to population aging. This research corroborates the demystification of Malthusianism, whose main idea attaches too much importance to the population volume in the environmental debate to the detriment of other demographic variables, as well as strengthens the need to create and consolidate a systematic line of research on "consumer demography".

Keywords: population-environment; consumption; demographic transition; electricity.

\section{Introdução}

Impacto ambiental, desenvolvimento sustentável e economia verde são assuntos que foram bastante discutidos e pesquisados no meio científico durante as últimas décadas, principalmente no que se refere ao papel do homem nos processos de mudanças climáticas globais. É majoritário entre os cientistas o entendimento da responsabilidade do homem nesse processo de mudanças climáticas, vide os sucessivos relatórios do Painel Intergovernamental sobre Mudanças Climáticas IPCC, notadamente o $4^{\circ}$ Relatório do IPCC (2007) (Hogan, 2009). Nesse contexto, a necessidade de se entender a componente e responsabilidade humana nos processos ambientais se tornou predominante nas conferências e fóruns mundiais relacionados ao tema.

No entanto, Hogan (2009) afirma que as ciências humanas nem sempre estiveram devidamente presentes no debate e que no Brasil, especificamente, só recentemente as dimensões humanas foram incorporadas nos estudos e pesquisas relacionadas às mudanças ambientais globais.

Historicamente, o componente demográfico foi inserido na problemática ambiental sob a luz do malthusianismo, cuja ideia principal era que a sobrevivência humana estava ameaçada pelo crescimento populacional devido a uma hipotética escassez de alimentos ou, mais recentemente, sob $\mathrm{o}$ aspecto do crescimento econômico. $\mathrm{O}$ autor desta teoria, Thomas Malthus, em seu famoso postulado datado do final do século XVIII (Malthus, 1798), projetava que o crescimento populacional apresentava um ritmo maior que a produção de alimentos e não haveria recursos naturais disponíveis para subsidiar tantas pessoas. Malthus foi um dos primeiros autores a relacionar as dimensões população e ambiente, debate este que, com o desenvolvimento ao longo do tempo, foi sendo incorporado ao escopo de estudo da ciência demográfica e sendo estabelecido um campo de pesquisa denominado População-Ambiente (P-A) (D'Antona, 2017). 
Apesar do relevante impacto e influência na sociedade e nas ideologias que nortearam as políticas de população nos séculos XIX e XX (Hogan et al., 2010), as previsões de Malthus não se concretizaram como ele previu e a própria história mostrou que a relação aumento populacional e esgotamento dos recursos naturais não apresenta um comportamento linear.

Com o processo de transição demográfica ${ }^{1}$ já avançado em grande parte do mundo, as taxas de fecundidade caíram a níveis abaixo do nível de reposição da população e em grande parte dos países já evidencia uma diminuição das taxas de natalidade há algumas décadas. Assim, em alguns países as taxas de crescimento populacional já se encontram relativamente baixas, com casos inclusive de países já com decréscimo populacional (ONU, 2019). Portanto, com a diminuição do incremento populacional, sobretudo nos países desenvolvidos e que contribuem significativamente com as emissões de gases de efeito estufa, era de se esperar que os efeitos do homem à natureza também diminuíssem. No entanto, o que se viu foi justamente o contrário (Mello \& Hogan, 2007), pois simultaneamente à redução no ímpeto do crescimento populacional mundial, houve um acréscimo na pressão ambiental. Ou seja, apenas o crescimento populacional não explicaria por si só as pressões sobre o ambiente como se supunha (Hogan, 2007; Hogan et al., 2010; Ojima, 2011).

Desse modo, apesar de significativos avanços na literatura dedicada ao tema, ainda encontram-se estudos que tratam a população-ambiente ( $\mathrm{P}-\mathrm{A})$ a partir dessa abordagem malthusiana, em que o esgotamento dos recursos naturais e até mudanças climáticas apresentariam relação direta com o crescimento absoluto da população (Hogan, 2007; Ojima, 2011). Exemplo disso é o artigo com grande repercussão na mídia publicado pela The Lancet e que coloca em destaque que "as projeções [populacionais] de encolhimento da população mundial apresentam implicações positivas para o meio ambiente, mudanças climáticas e produção de alimentos" (Vollset et al., 2020, p. 2, tradução nossa). Da mesma forma, os modelos que projetam os cenários de mudança climática incorporam sempre o crescimento absoluto da população como variável forçante negativa para as mudanças climáticas (Jiang \& Hardee, 2011; Ojima, 2011).

É importante ressaltar que esta pesquisa não nega o tamanho da população como um fator importante na pressão no ambiente. É de se esperar que uma população de oito bilhões de pessoas necessite de mais recursos do que uma de um bilhão. A crítica aqui realizada é o reducionismo e a fragilidade desse discurso quando não são incorporados outros fatores demográficos nessa relação, ainda mais em um contexto em que as projeções vislumbram contínua redução da fecundidade, diminuição do crescimento e até redução populacional em diversos países.

Assim, o objetivo nesse artigo é apresentar elementos que comprovem a necessidade de incorporar outros aspectos da dinâmica demográfica nas análises de P-A. Portanto, à luz da literatura recente sobre o papel da população no desempenho ambiental

\footnotetext{
${ }^{1}$ A Teoria da Transição Demográfica explica como as populações passaram de uma condição pré-moderna de estabilidade, com alta mortalidade e fecundidade, para outra condição quase estável pós-moderna, com mortalidade e fecundidade baixas. As principais consequências da Transição Demográfica é a diminuição do crescimento populacional e o envelhecimento da sua estrutura etária.
} 
(Guzman et al., 2009; Martine \& Schensul, 2013), discutiremos como um contexto pós-transicional, período caracterizado por um crescimento populacional muito baixo (e potencialmente negativo em alguns casos) e uma estrutura etária envelhecida, pode acarretar significativos impactos ambientais. Martine (2012, p. 12) assegura que "a dinâmica demográfica é bem mais complexa e sua importância nos processos ambientais em curso é muito maior do que os meros números absolutos". De fato, limitar o componente demográfico no debate ambiental apenas ao tamanho populacional é desperdiçar toda a potencialidade que a análise demográfica poderia oferecer para o entendimento da relação P-A.

Com a evolução da discussão no meio acadêmico e o entendimento cada vez maior de que é necessário superar o discurso hegemônico do malthusianismo, pelo menos no campo da demografia, surgiram perguntas sobre quais outros fatores demográficos assumiriam importância na questão das mudanças climáticas globais. Martine (2012) enaltece a importância da ampliação do debate com a incorporação de outras variáveis demográficas, como fecundidade, mortalidade, morbidade, migração, nupcialidade e estrutura etária.

É nesse contexto que a demografia se atenta ao padrão de consumo da população para melhor compreender a relação P-A, conforme relatado por De Sherbinin \& Curran (2004). Segundo os autores, o consumo não é novidade nos estudos ambientais. No entanto, esse componente é abordado no discurso ambiental de forma superficial ou até mesmo equivocado (De Sherbinin \& Curran; 2004), misturado, ainda, com vieses ideológicos, onde não há uma devida análise da variável consumo além da óptica malthusiana. A proposição dos estudos de população-ambiente em entender o consumo a partir de outras variáveis demográficas se caracteriza em um campo de estudo profícuo e, talvez, essa seja a maior contribuição da demografia para as ciências ambientais, o que poderá trazer grandes subsídios para mitigação e adaptação às mudanças ambientais globais. Para uma melhor compreensão da inserção da variável consumo no debate sobre População e Ambiente e de que forma isso ocorreu historicamente, consultar Mello \& Sathler (2015).

É nesse contexto que as pesquisas demográficas entenderam que a importância do consumo nos estudos de P-A não se deve ater apenas a uma crítica de modelo econômico de desenvolvimento vigente, mas principalmente ao fato de que o consumo é uma variável cujo comportamento é intrinsecamente relacionado à dinâmica populacional. Transição demográfica, estrutura etária, composição familiar, expectativa de vida, equidade entre os gêneros, fluxos migratórios, urbanização, composição e tamanho das famílias e outras dimensões demográficas são de fundamental importância para compreender os padrões de consumo e deveriam ser incorporados às estimativas das mudanças climáticas em detrimento do volume absoluto da população (Pebley, 1998; Liddle, 2011; Modesto, 2011; Martine, 2012) que, na prática, contribui mais para a manutenção do status quo ambiental.

Dessa forma, dado que o Brasil e grande parte do mundo vivenciam profundas transformações demográficas, condicionando o envelhecimento de sua população, mudanças nos arranjos familiares e, consequentemente, uma tendência de menos pessoas por domicílio, a dinâmica demográfica é um fator preponderante na definição do padrão e do nível do consumo agregado, logo, com consequentes reflexos na pressão exercida pela população ao meio ambiente. 
Vários trabalhos têm feito um exercício teórico-analítico sobre o tema, atribuindo ao consumo um papel de protagonista quando se debate o impacto da população no ambiente. Além do trabalho seminal de De Sherbinin \& Curran (2004), já citado anteriormente, pode-se extrair conclusões semelhantes em Carmo (2007); Mello \& Hogan (2007); Mello (2009); Satterthwaite (2009); Martine (2009); Hogan et al. (2010); Liddle \& Lung (2010); Liddle (2011); Modesto (2011); Ojima (2011); Martine et al. (2012); Ojima (2012). No entanto, apesar dessa literatura trazer significativo avanço para o debate emergente, De Sherbinin \& Curran (2004) afirmam que são verificados poucos trabalhos de caráter metodológico que operacionalizam e quantificam os efeitos da dinâmica demográfica sobre o consumo agregado e os seus potenciais efeitos ambientais. Os autores ainda enfatizam os grandes desafios metodológicos da área, sugerindo algumas opções de escala de análise e métrica de consumo, por exemplo. É nessa lacuna metodológica que este trabalho busca se inserir e contribuir para a discussão.

Segundo a lógica neomalthusiana, a diminuição do ritmo de crescimento populacional e do volume absoluto da população deveria induzir a uma menor demanda por recursos naturais (Hogan et al., 2010; Mello \& Sathler, 2015). No entanto, a hipótese a ser testada aqui é como a diminuição e manutenção dos baixos níveis de fecundidade podem exercer um efeito justamente contrário, pelo menos a curto e médio prazo. Ou seja, mesmo com menos pessoas em uma população, apenas a transição da estrutura etária da população e outros arranjos demográficos poderiam exercer uma maior pressão e demanda sobre os recursos naturais através do aumento no consumo agregado. Deste modo, a partir deste arcabouço teórico, o objetivo do estudo é analisar o consumo de energia elétrica domiciliar per capita considerando estágios do ciclo de vida familiar/domiciliar no Brasil e padronizar o comportamento do consumo agregado com o envelhecimento populacional/domiciliar.

Como referenciado anteriormente, as potencialidades das opções metodológicas para entender o consumo a partir das variáveis demográficas ainda estão sendo desbravadas. Nesse sentido, este trabalho adotou as seguintes opções metodológicas: como fonte de dados, foi utilizada a Pesquisa de Orçamento Familiares - POF 2008/2009; em relação à métrica de consumo, optou-se pelo consumo de energia elétrica; como escala de análise, verificou-se mais adequado o domicílio; para caracterização demográfica do domicílio, foi sugerida a idade do chefe do domicílio; e, por fim, foi proposta a técnica demográfica de Padronização Direta de taxas para alcançar o objetivo proposto. No tópico 3 do trabalho, são melhor discutidas as teorias que justificaram as escolhas realizadas.

Dessa forma, espera-se corroborar a discussão sobre a relação entre mudanças na estrutura etária e o consumo, bem como argumentar sobre as relações entre a transição demográfica, novos arranjos familiares e aumento do número de domicílios sobre o padrão de consumo.

\section{Dinâmica demográfica e consumo: pontos de convergência}

A partir do final da primeira metade do século $\mathrm{XX}$, a população brasileira inicia o processo de transição demográfica, saindo de um regime de altas para baixas taxas de mortalidade e fecundidade. Além disso, a expectativa de vida ao nascer 
aumentou em mais de 30 anos nos últimos 60 anos e a Taxa de Fecundidade Total (TFT) ${ }^{2}$, que era de 6,2 filhos por mulher em 1960, atinge a marca de 1,8 em 2010 (IBGE, 2013). As quedas na mortalidade e, especialmente, na fecundidade ocasionaram uma profunda e, provavelmente, irreversível mudança na estrutura etária brasileira. Assim, a população de 60 anos ou mais que representava $5,1 \%$ da população total em 1970, passou para 10,8\% em 2010 e, segundo as projeções, deverá representar cerca de $25 \%$ da população na metade do século XXI.

Com isso, outra consequência da mudança da estrutura etária é o envelhecimento das famílias e/ ou dos domicílios. Ou seja, com uma estrutura etária mais velha e menos crianças, os domicílios também estão mais envelhecidos. Como proxy deste envelhecimento nos domicílios, verifica-se que a idade média do chefe do domicílio aumentou de 43,2 em 1991 para 45,6 em 2010 (Ojima et al., 2014).

A esse processo de reduções das taxas de fecundidade e mortalidade observadas nas sociedades contemporâneas, bem como suas causas e consequências, é atribuída a denominação Primeira Transição Demográfica - FDT (Lesthaeghe, 2010). Um outro processo relacionado e consequente da FDT é a Segunda Transição Demográfica - SDT. Esta segunda transformação nos padrões demográficos está associada à continuação da queda da fecundidade, crescimento negativo, aumento da diversidade de uniões e arranjos familiares, desconexão entre casamento e procriação e aumento dos divórcios. (Lesthaeghe, 2010). De um modo geral, uma das marcantes características da SDT foi o seu impacto nas famílias, alterando a sua estrutura, seu comportamento e aspirações.

Deste modo, o que se observou na SDT de forma destacada foi uma desinstitucionalização da família nuclear e uma maior heterogeneidade nos arranjos familiares. Há ainda uma predominância do arranjo domiciliar de "casal com filhos", mas se observa a redução na sua importância relativa e o aumento de arranjos monoparentais, principalmente chefiadas por mulheres, casais sem filhos e arranjos unipessoais (Medeiros \& Osório, 2000; Arriagada, 2007).

Outro processo associado às mudanças demográficas é a redução da quantidade de pessoas por domicílio. Segundo dados dos Censos Demográficos (IBGE, 2010), os domicílios no Brasil apresentavam, em média, 5,3 moradores em 1970, chegando a 3,3 moradores em 2010. Além disso, observou-se um descompasso entre os crescimentos da população e dos domicílios. Enquanto a população cresceu em média $1,77 \%$ ao ano entre 1980 e 2010, o número de domicílios mostra outro padrão de crescimento, com incremento médio anual em torno de 3\% ao ano no mesmo período. Assim, a população que dobrou entre 1970 e 2010, hoje reside em um número de domicílios que mais triplicou neste mesmo período. Ou seja, o crescimento dos domicílios é maior que a própria população. Esse processo de "mais domicílios e menos pessoa por domicílio" está intrinsecamente ligado à queda da fecundidade e envelhecimento populacional e familiar no Brasil e constitui o processo de mudança no ciclo de vida dos domić́lios brasileiros.

\footnotetext{
${ }^{2}$ A TFT representa o ${ }^{\circ}$ médio de filhos que uma mulher teria ao final do seu período reprodutivo se experimentasse ao longo da vida as taxas específicas de fecundidade observadas naquele momento.
} 
Constatadas essas mudanças na dinâmica populacional do Brasil causadas pela FDT e SDT, pode-se aventar possíveis variações nos níveis de consumo do brasileiro decorrentes da mudança da estrutura etária e do ciclo de vida dos domicílios (Vanwey et al., 2004; Lee et al., 2006; Lee \& Mason, 2010). Zagheni (2011), com dados dos EUA, mostrou os diferentes perfis de consumo per capita de diversos bens e serviços por idade. Foi verificado que o consumo de alguns bens tem seus ápices no final da idade adulta (entre 50 e 60 anos), como gasolina, roupas e comidas. Já outros bens apresentam um consumo crescente à medida em que avançam na idade, como gás natural e eletricidade. Ainda segundo a mesma pesquisa, as emissões médias de dióxido de carbono $\left(\mathrm{CO}_{2}\right)$, utilizado como um proxy do consumo de todos os bens considerados, aumentam com a idade até os 60 anos.

Na mesma linha de resultados, estudos como os de Lee \& Mason (2010), Liddle \& Lung (2010) e Liddle (2011) mostram um comportamento geral do consumo crescendo com o avanço das idades. Em geral, o ápice do consumo está nas idades entre 60 e 70 anos com posterior declínio. Deste modo, se o nível de consumo é diferente e crescente ao passar das faixas etárias, é coerente propor que a transição da estrutura etária afetará o consumo agregado da população. Ojima (2012) especula sobre essa tendência de que mesmo ao reduzir o ritmo de crescimento populacional e até mesmo se reduzir a população, haveria uma elevação no consumo devido ao envelhecimento populacional.

Uma explicação para este comportamento é que o consumo é uma variável derivada da renda pessoal ou da família: quanto maior a renda, espera-se maior consumo. Por sua vez, a renda, seja ela individual ou familiar, também é sensível à idade ou composição etária da família. Alguns estudos, como Leone et al. (2010) e Maia \& Sakamoto (2014), tentaram explicar como as mudanças demográficas, principalmente aquelas relacionadas às transformações na estrutura e composição dos domicílios, cooperaram para o aumento da renda domiciliar per capita no Brasil. Neste cenário, levanta-se a hipótese de que o envelhecimento populacional e as mudanças na estrutura das famílias modificam o ciclo de vida da família e se entrelaçam como causadores do aumento de renda per capita. Logo, espera-se que aumente o consumo. Dessa forma, a discussão entre mudanças demográfica e alterações nos níveis de consumo perpassa, em grande parte, pela alteração da renda do indivíduo ou do agregado que, por sua vez, também é sensível a dinâmica demográfica (Medeiros \& Osório, 2000; Liu et al., 2003; Jiang \& O'neill, 2007, Yu \& Liu, 2007; Barros et al., 2008; Druckman \& Jackson, 2008; Lins, 2010; Tung, 2011; Carvalho \& Alves, 2012; Martine et al., 2012; Silva et al., 2012; Zanon et al., 2013).

Com isso, pode-se afirmar que as mudanças na distribuição das famílias por idade, tipo e tamanho exercem efeitos sobre o consumo das famílias, com consequentes impactos sobre o ambiente e o uso de recursos naturais (Liu et al., 2003; De Sherbinin \& Curran, 2004; Yu \& Liu, 2007).

\section{Proposta metodológica: analisando a "idade dos domicílios" e o consumo}

A proposta metodológica deste artigo é verificar se seria possível identificar diferenciais de consumo considerando uma característica demográfica no Brasil e analisar o comportamento do consumo se o país apresentasse outra estrutura demográfica. 
Mas antes do detalhamento de cada etapa da metodologia, é preciso esclarecer que este trabalho teve que fazer três opções metodológicas: a métrica do consumo; a unidade de análise; e o localizador da fase do ciclo de vida (ou caracterização demográfica) dos domicílios.

A unidade de análise privilegiada pelo trabalho é o domicílio, pois as famílias e/ou domicílios são os usuários finais ou beneficiários da maioria das formas de consumo (De Sherbinin \& Curran, 2004). Segundo Tung (2011), uma dificuldade conceitual de atribuição de consumo para os indivíduos é que alguns tipos de consumo são de bens coletivos e pode haver economias de escala dentro dos domicílios. Além disso, as pesquisas de despesas da família, que são as principais fontes de microdados de consumo, geralmente não relatam consumo individual (Tung, 2011). Essa preferência faz sentido na medida em que consideramos que grande parte do consumo de um indivíduo é compartilhada entre os membros do domicílio através de bens duráveis e não duráveis. Outra potencialidade do domicílio como unidade de análise é que esta escala permite captar não só o processo de envelhecimento populacional, mas também as mudanças no tamanho e composição das famílias (Silva et al., 2012).

Como unidade de consumo, será utilizado o gasto de energia elétrica do domicílio, por entender que essa métrica representa, em grande parte, o estilo de vida da família. Para isolar o efeito da quantidade de pessoas no domicílio, será utilizado o consumo de energia per capita do domicílio. Uma série de outras vantagens para o seu uso são levantadas por De Sherbinin \& Curran (2004), tais como: fácil de mensuração, facilmente convertida em outras unidades (joules, calorias, watts, etc), e cada unidade de consumo de energia é ambiental- mente representativo, tanto em termos de poluição como em emissão de gases de efeito estufa. Penã (2013) e Del Guercio (2015) bem discorrem sobre a pertinência de se utilizar o gasto de energia elétrica como uma boa aproximação ou proxy do consumo do domicílio, enfatizando a boa aplicabilidade dessa unidade de consumo, que está intimamente ligada à emissão de gases que aceleram o processo de mudanças climáticas globais, bem como relacionam essa medida com outras variáveis associadas à ela, como: grau de desenvolvimento do país, renda das famílias, período de análise, arranjos domiciliares e coorte de nascimento.

Por fim, a última escolha metodológica é o critério para localizar o domicílio em seu estágio do ciclo de vida, sendo uma tentativa de quantificar o envelhecimento do domicílio. Esta opção metodológica se baseou na Teoria do Ciclo de Vida (TCV), pois trata-se de uma ferramenta analítica útil para compreensão da relação entre consumo e estrutura etária (Lee et al., 2006; Lee \& Mason, 2010; Tung, 2011). A hipótese básica da TCV é que o comportamento das pessoas e das famílias, com destaque para o consumo, muda na medida em que envelhecem e isso implicaria em dizer que o perfil de consumo de uma população é condicionado ou influenciado por sua estrutura etária.

Este trabalho entende que tanto os comportamentos como o consumo diferem não somente pela idade das pessoas do domicílio, mas também pelo tipo de arranjo familiar. Uma conjugação entre as idades dos moradores e o arranjo familiar apresentado talvez seja um indicador mais abrangente quando o intuito é analisar as mudanças nos padrões de consumo (Fernandez, 2006), conjugando em um único indicador às mudanças provocadas pela primeira e segunda transições demográficas. 
No entanto, o interesse desse trabalho é apenas quantificar o quão envelhecido é o domicílio, uma aproximação para se entender o que seria a "idade do domicílio", sem ponderar, neste momento, pela situação ou arranjo familiar ${ }^{3}$.

Assim, propõe-se como medida síntese para poder estimar a "idade do domicílio" a partir da idade do chefe do domicílio. A escolha deste indicador se mostra adequada já que ele consegue representar as mudanças da estrutura etária da população a nível domiciliar. Jiang \& O’Neill (2007) afirmam que a composição da população por idade do chefe do domicílio reflete não apenas a estrutura etária da população, mas também a composição etária das famílias.

Os dados utilizados neste trabalho foram os microdados da Pesquisa de Orçamento Familiar (POF) da sua última edição, realizada entre os anos de 2008/2009 (IBGE, 2009). Esta pesquisa é realizada pelo Instituto Brasileiro de Geografia e Estatística - IBGE e tem por objetivo obter informações sobre a estrutura de orçamentos (gastos, consumo e rendimentos), estado nutricional e condições de vida das famílias e da população brasileira (IBGE, 2008), e tem como unidade básica da coleta da informação os domicílios particulares, sendo as unidades de análise os domicílios e os indivíduos. Dessa pesquisa foi possível extrair a informação da estrutura domiciliar, bem como o consumo de energia elétrica do domicílio.

Assim, a primeira etapa consistiu em calcular taxas específicas de consumo (TEC) por cada estágio do ciclo de vida do domicílio. Essa TEC refere-se ao quociente entre a quantidade de con- sumo de energia elétrica per capita dos domicílios de determinada fase do ciclo de vida e o número de domicílios nesta mesma fase do ciclo de vida. Assim, entendemos a TEC como a média do consumo de energia elétrica domiciliar per capita segundo a fase do seu ciclo de vida. Deste modo, podemos representar a TEC como:

$$
{ }_{n} \text { TEC }_{x}=\frac{{ }_{n} \text { CEDpercap }}{x}
$$

Onde,

${ }_{n} \boldsymbol{T E} \boldsymbol{C}_{\boldsymbol{x}}=$ Taxa específica de consumo de energia elétrica do domicílio per capita entre as idades $\mathrm{x}$ e $\mathrm{x}+\mathrm{n}$, em que essas idades se referem à idade do chefe do domicílio;

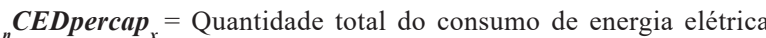
domiciliar per capita pelos domicílios entre as idades $\mathrm{x}$ e $\mathrm{x}+\mathrm{n}$, em que essas idades se referem à idade do chefe do domicílio;

${ }_{n} \boldsymbol{D o m}_{\boldsymbol{x}}=$ Número total de domicílios entre as idades $\mathrm{x}$ e $\mathrm{x}+\mathrm{n}$, em que essas idades se referem à idade do chefe do domicílio.

No denominador de taxas demográficas, deve-se utilizar o conceito de pessoas-ano, que é uma medida de exposição ao risco ao evento que se pretende mensurar. Devido à dificuldade de se mensurar essa quantidade de exposição ao risco, é utilizada como estimativa dessas pessoas-ano a quantidade de pessoas no meio do ano, pressupondo que o evento estudado ocorre de maneira uniforme no ano. No caso deste estudo, o denominador deveria ser entendido como domicílios-ano, ou seja, a quantidade de domicílios que contribuíram ao risco de consumir energia elétrica. Como estimativa desta quantidade de domicílios-ano, foi utilizada a própria quantidade de domicílios informada pela pesquisa, já que a pesquisa ocorre durante todo um período de um ano. Assim, no numerador tem-se o total de

\footnotetext{
${ }^{3}$ Dada a relativa complexidade dos efeitos do arranjo domiciliar, este será discutido separadamente nos resultados e espera-se desenvolve-lo mais detalhadamente em trabalhos futuros.
} 
consumo de energia elétrica domiciliar per capita e no denominador o total de domicílios.

A segunda etapa do trabalho consistiu no cálculo de uma medida agregada de consumo de energia elétrica, definida como Taxa bruta de consumo de energia elétrica do domicílio per capita - TBC. A interpretação a ser dada a TBC é a quantidade média de consumo de energia elétrica domiciliar per capita por domicílio e pode ser representada da seguinte maneira:

$$
T B C=\frac{C E \text { Dpercap }}{\text { Dom }}
$$

TBC $=$ Taxa bruta de consumo de energia elétrica do domicílio per capita;

CEDpercap = Quantidade total do consumo de energia elétrica domiciliar per capita;

Dom $=$ Número total de domicílios.
A TBC encontrada para o Brasil em 2009 foi de 59,5 kWh, que pode ser interpretado como a quantidade média de consumo per capita de energia elétrica por domicílio. Este é o nível de consumo de energia elétrica domiciliar per capita. Já a série de TEC's encontrada está representada na Figura 1.

Verifica-se, portanto, que o nível de consumo de energia elétrica domiciliar per capita aumenta na medida em que o chefe do domicílio é mais velho. Esse comportamento corrobora com a hipótese levantada de que o consumo é uma variável que sofre efeitos da composição da população e que aumenta na medida em que os domicílios envelhecem, lembrando que este trabalho está adotando a idade do chefe do domicílio como uma representação do envelhecimento domiciliar. Isso pode ser explicado pelo fato de que a renda monetária das pessoas e da

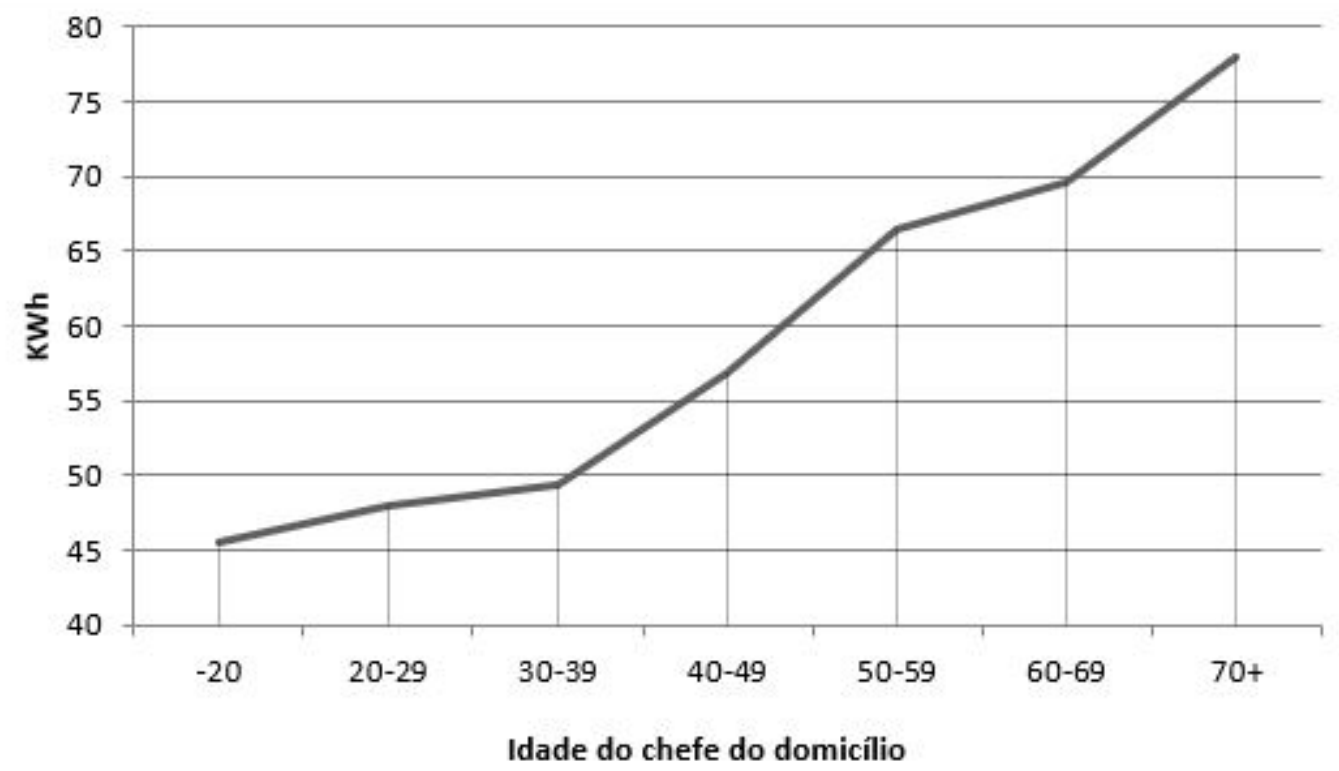

FIGURA 1 - TEC dos domicílios por idade do chefe do domicílio, Brasil, 2009.

FONTE: IBGE (2008), Microdados da POF 2008/2009. 
combinação agregada dos membros de um domicílio, de uma forma geral, é crescente durante a vida.

Outro fato que ajuda a explicar esse comportamento é o efeito das mudanças na composição dos domicílios, principalmente no que se refere à diminuição do número de moradores. Desta forma, tem-se o seguinte cenário: as pessoas do domicílio estão envelhecendo e, juntamente com a renda dessas pessoas aumentando, há menos pessoas nos domicílios. Esse conjugado de aumento da renda com o passar da idade e diminuição do número de pessoas no domicílio faz com que a renda per capita aumente nos domicílios com chefes mais velhos (Maia \& Sakamoto, 2014).

No entanto, a renda não explica toda a relação entre consumo e dinâmica demográfica. As consequências das mudanças na estrutura e composição dos domicílios podem ser fatores que influenciam diretamente o nível de consumo do domicílio, sem necessariamente passar pelo fator renda. Como ilustração desta hipótese, pode-se afirmar que os domicílios têm cada vez menos pessoas para compartilharem bens de consumo comuns de energias, como geladeira, fogão (caso elétrico), chuveiro elétrico, etc., aspecto que representa o efeito de escala dessa relação, aumentando assim o consumo per capita.

Desse modo, pode-se afirmar que, na medida em que o domicílio envelhece, eles tendem a ter menos pessoas por domicílio e apresentar arranjos domiciliares sem crianças, elevando o efeito de economia de escala no consumo, como apontam Menz $\&$ Welsch (2012). Além disso, deve-se apresentar um maior nível de renda, o que também deve contribuir para elevar o consumo. Ou seja, tem-se fatores de confundimento autocorrelacionados agindo nessa relação.
Portanto, é imperativo ressalvar que a análise desses resultados deve ser devidamente ponderada por esses efeitos que a renda e a composição domiciliar causam no aumento do consumo, além da mudança da estrutura etária que é o objeto principal de análise deste trabalho.

\subsection{O consumo dos arranjos domiciliares}

A análise descritiva do consumo de energia elétrica domiciliar per capita por tipos de arranjos familiares permite supor que há diferenças de nível de consumo que podem ser explicadas para além da elevação da renda domiciliar. Para tanto, as TEC descritas na etapa anterior serão calculadas também segundo os tipos de arranjo domiciliar que serão criados a partir da relação de parentesco informado na POF. Para fins dessa análise, os arranjos considerados foram:

- Unipessoal;

- Casal sem filhos;

- Casal com filhos (nuclear);

- Monoparental feminino; $\mathrm{e}$

- Outros.

A escolha desses arranjos se justifica por representar a maioria das famílias brasileiras (Alves et al., 2010). Assim, pode-se perceber (conforme a Figura 2) que as maiores TEC encontradas foram para os domicílios unipessoais e casais sem filhos, o que confirma, para o caso brasileiro, o que a literatura havia discutido. Em média, os domicílios unipessoais apresentaram um consumo per capita de energia elétrica de $116,09 \mathrm{kWh}$ e os formados por casais sem filhos, 70,09 kWh. 


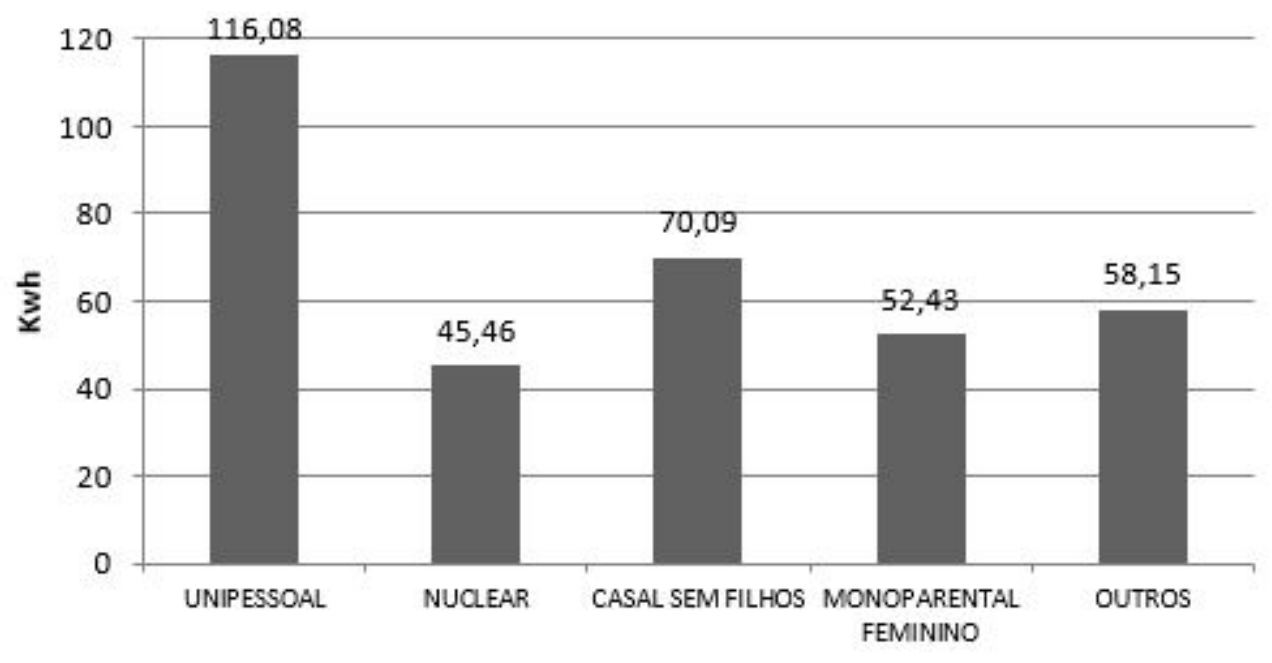

Arranjo domicliar

FIGURA 2 - TEC por arranjo domiciliar no Brasil - 2009.

FONTE: IBGE (2008), Microdados da POF 2008/2009.

O arranjo unipessoal se destaca dos demais, pois nos domicílios que apresentam esse arranjo fica mais evidente o papel do efeito de escala, ou seja, há mais bens de consumo servindo apenas uma pessoa. Além disso, pode haver fatores associados agindo sobre os domicílios unipessoais, como maior renda e a própria estrutura etária desse tipo de domicílio. Em seguida, o arranjo domiciliar que apresenta o segundo maior nível de consumo de energia per capita é o de casal sem filhos. Esses dois tipos de arranjos que possuem as maiores TEC, unipessoal e casal sem filhos, são justamente os arranjos com menor número de pessoas e ausência de crianças. Já o arranjo que apresentou a menor TEC foi o nuclear: cerca de 45,46 kWh. De acordo com os dados, a pessoa que compõe o domicílio unipessoal consome mais do que o dobro do que uma pessoa que está inserido em um domicílio nuclear.
Assim, os arranjos domiciliares que apresentam os maiores níveis de consumo per capita, são aqueles que justamente estão apresentando maior ritmo de crescimento em relação aos demais no país. Segundo Alves \& Cavenagui (2012), esses dois tipos de arranjo familiar aumentaram sua participação no Brasil em $20 \%$ e $54 \%$ entre 1980 a 2010 , respectivamente. Já o arranjo que possui a menor TEC, casal com filhos, é justamente o que apresenta a maior perda na participação relativa nos domicílios brasileiros, saindo de 65\% dos domicílios brasileiros em 1980 para 52,5\% em 2010, uma diminuição na ordem de 24\% (Alves \& Cavenaghi, 2012).

Provavelmente, assim como o próprio envelhecimento populacional, esse caminho para uma nova composição dos domicílios brasileiros quanto a sua composição e seus arranjos familiares continuará nas próximas décadas e com caráter irreversível. Dessa 
forma, o aumento da participação dos arranjos que mais consomem energia elétrica e a diminuição dos que menos consomem tenderá a um maior nível de consumo no futuro pelos domicílios brasileiros. Esse é um resultado que merece destaque nessa pesquisa e que descontrói, em certa medida, o argumento, recorrente no senso comum, de que famílias menores ajudariam na diminuição do impacto da população no ambiente, justificando políticas de controle da natalidade.

\section{O impacto da estrutura etária no consumo energético total}

Conforme já mencionado, a literatura aponta que, como reflexo do envelhecimento populacional, haveria também uma tendência de envelhecimento dos chefes dos domicílios brasileiros. Portanto, uma das opções para se verificar o impacto da transição demográfica brasileira no consumo energético seria avaliar uma estrutura etária padrão que contivesse uma maior proporção de domicílios com chefes em idades mais avançadas do que foi observado em 2009. Entretanto, para isso, seria necessário obter projeções da população brasileira considerando a distribuição etária dos chefes de domicílio. Dada a dificuldade metodológica de se obter projeções com este nível de detalhamento, optou-se por elaborar uma análise reversa, na qual se aplicou os níveis de consumo por idade e total obtidos para o ano de 2009 a uma distribuição etária dos chefes de domicílio conhecida.

Portanto, utilizamos a distribuição etária dos domicílios obtidos no Censo Demográfico 1970 (2015), por entendermos que se tratava de um contexto em que o processo de transição demográfica apresentava seus primeiros reflexos mais evidentes na estrutura etária da população do país, mas que ainda mantinha uma predominância de país jovem. A Figura 3 confirma essa suposição, pois ilustra a distribuição etária da população total brasileira a partir dos Censos Demográficos de 1970 e 2010.

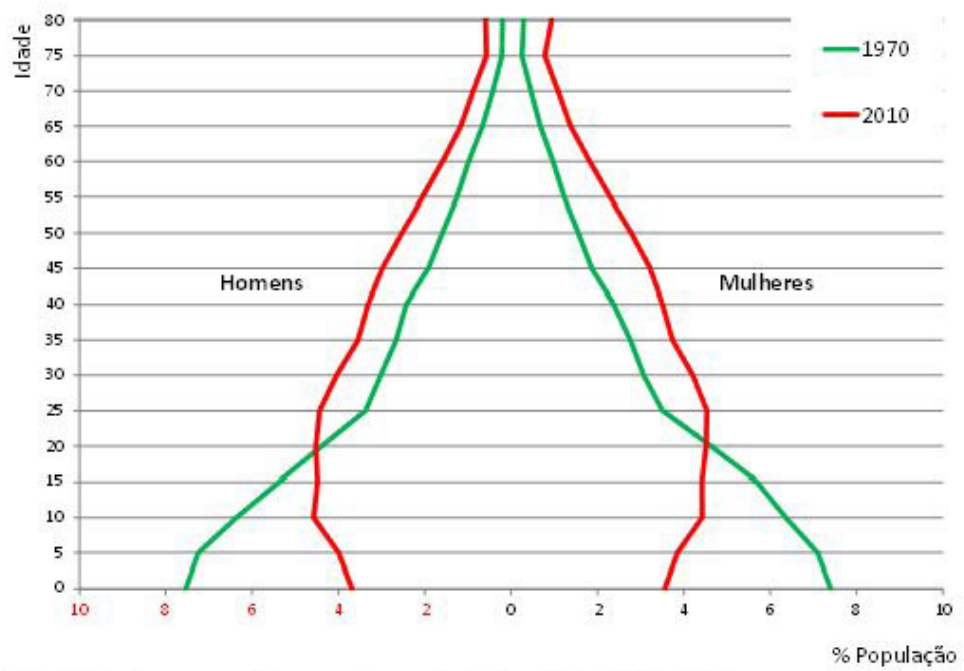

FIGURA 3 - Estrutura etária e sexo da população brasileira, 1970 e 2010.

FONTE: IBGE (2010), Censos Demográficos 1970 (2015) e 2010. 
Fato que, associado ao apresentado pela Figura 4, corroboram a transição da estrutura etária dos domicílios. Ou seja, houve um envelhecimento significativo da estrutura etária dos domicílios, identificado neste trabalho pelo envelhecimento das idades dos chefes de domicílio.

Assim, tendo definido a estrutura etária padrão dos domicílios por idade do chefe, procedeu-se à padronização das taxas de consumo obtidas para o ano de 2009. Tendo obtido as Taxas Específicas de Consumo por "Idade do Domicílio" e o consumo total de energia elétrica per capita domiciliar (TBC), buscou-se verificar como a TBC do Brasil em 2009 se comportaria caso os domicílios apresentassem a distribuição etária dos domicílios de 1970. Em outros termos, qual seria o nível de consumo ener- gético dos domicílios brasileiros se a estrutura etária dos domicílios se comportasse como em um período ainda inicial da transição demográfica.

A formulação da padronização adotada pelo trabalho consta a seguir:

Onde,

$$
T B C_{p . d}=\frac{\sum_{x} T E C_{x} \cdot{ }_{n} \operatorname{Dom}_{x, s}}{\sum_{n} \operatorname{Dom}_{x, s}}
$$

$\boldsymbol{T B C}_{\boldsymbol{p} . \boldsymbol{d}}=$ Taxa bruta de consumo de energia elétrica domiciliar per capita padronizada por composição dos domicílios por fases do ciclo de vida; ${ }_{n} \boldsymbol{T E C _ { x }}=$ Taxa específica de consumo de energia elétrica do domicílio per capita entre as idades $\mathrm{x}$ e $\mathrm{x}+\mathrm{n}$, em que essas idades se referem à idade do chefe do domicílio;

${ }_{n}$ Dom $_{x, s}=$ Número ou proporção de domicílios a idade $\mathrm{x}$ e $\mathrm{x}+\mathrm{n}$ da estrutura adotada como padrão, onde essa idade se refere à idade do chefe do domicílio;

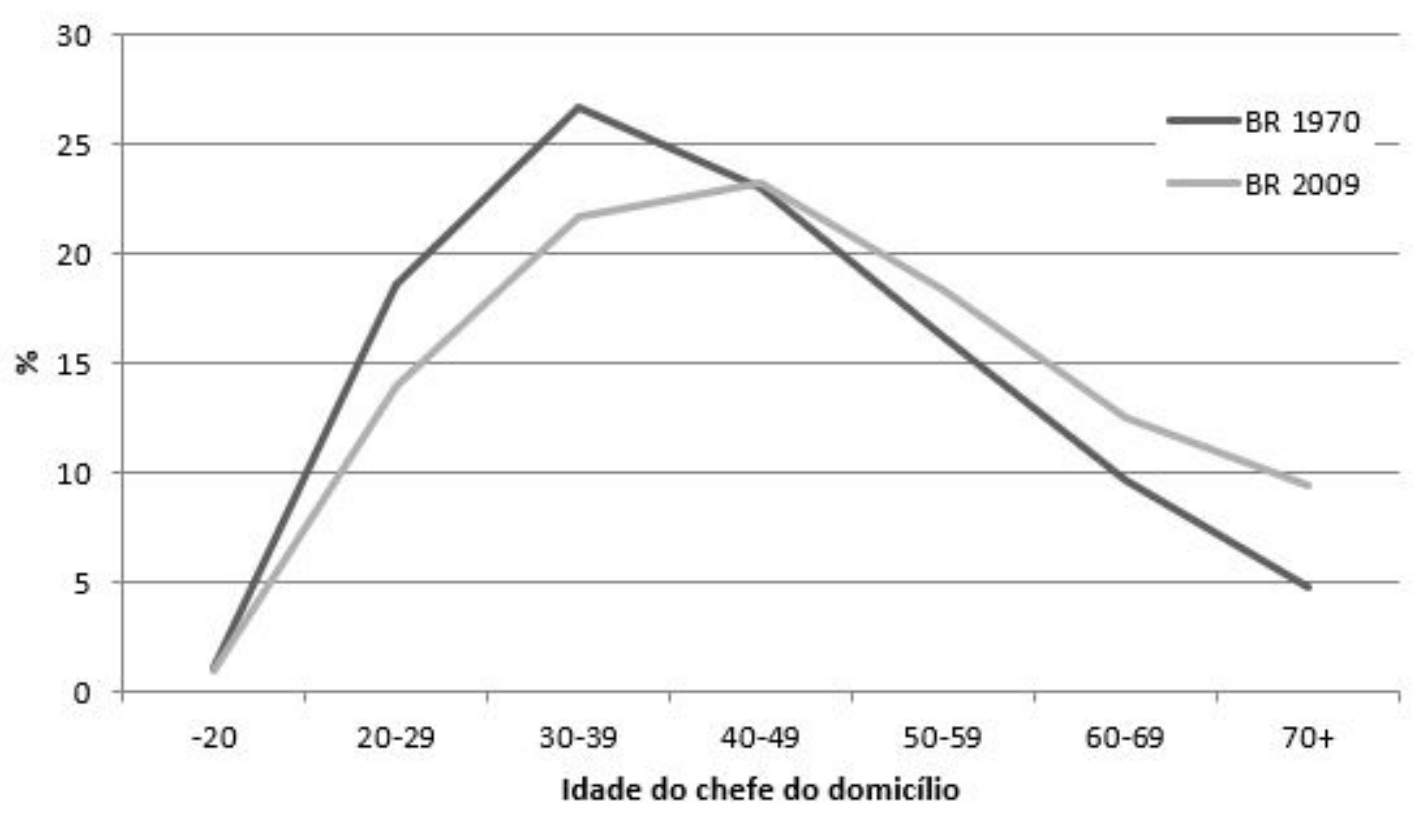

FIGURA 4 - Composição dos domicílios por idade do chefe do domicílio, Brasil, 1970 e 2009.

FONTE: IBGE (2008), Censo Demográfico 1970 (2015) e Pesquisa de Orçamentos Familiares 2008/2009. 
A

Faixas etárias dos chefes dos domicílios
TEC Brasil (2009)
B

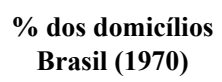

$\mathbf{A} * \mathbf{B}$

0,5

8,9

13,2

13,1

10,8

6,7

3,7

\begin{tabular}{lccc}
$70+$ & 78,0 & $4,7 \%$ & 3,7 \\
\hline TBC BRASIL 2009 & 59,5 & TBC BR $09 \mathrm{p} /$ BR 1970 & 56,9
\end{tabular}

FONTE: IBGE (2008), Censo Demográfico 1970 (2015) e Pesquisa de Orçamentos Familiares 2008/2009.

A TBC do Brasil em 2009 foi de 59,5 kWh e a Tabela 1 apresenta os resultados da padronização da TBC obtidos a partir dos dados da POF de 2009 na estrutura etária dos domicílios brasileiros do ano de 1970. Portanto, o resultado alcançado indica que se as TEC de 2009 fossem vivenciadas por uma população que tem a estrutura de idade dos chefes do domicílio do Brasil em 1970, teríamos uma TBC de $56,9 \mathrm{kWh}$. Uma diferença de 2,6 kWh a menos decorrente apenas da mudança da estrutura etária.

A diferença obtida entre as TBC pode parecer pequena à primeira vista, porém é importante lembrar que a TBC é uma medida per capita e ao generalizar essa diferença, que é individual, para toda a população brasileira, certamente se configura em uma diferença de níveis de consumo de energia relevante para o sistema elétrico brasileiro. Assim, se multiplicarmos essa diferença pelo total da população brasileira, obteríamos uma diferença de 520 mil MWh. Portanto, se a população brasileira identificada em 2009 apresentasse o mesmo padrão de consumo energético domiciliar, mas apresentasse a estrutura etária que tinha em 1970, esse seria o valor que o Brasil deixaria de consumir caso não tivesse passado pela transição demográfica.

Para se ter um parâmetro de comparação, a economia de energia elétrica obtida pela imposição do horário de verão entre 2012 e 2013 foi da ordem de 2.477 MWh (ONS, 2013). Caso esta mesma economia de energia tivesse ocorrido em todos os verões entre 1970 e 2009, o resultado seria um acumulado de economia de energia elétrica que representaria cinco vezes menor do que o aumento no consumo de energia nos domicílios brasileiros decorrente do envelhecimento no mesmo período.

\section{O futuro do consumo e população: notas exploratórias}

Segundo dados da Pesquisa Nacional por Amostra de Domicílios, houve um aumento da 
porcentagem de quase todos os bens de consumo duráveis presentes nos domicílios brasileiros, com destaque para a máquina de lavar, que em 2001 estava em 33,64\% dos domicílios e em 2011 passou para mais de $50 \%$. E para a geladeira, que passou de $85,12 \%$ para $95,75 \%$ no mesmo período. Ainda segundo dados da PNAD, o percentual de domicílios com acesso à internet saiu de 13,7 para 36,5 entre 2005 e 2011. O próprio aquecimento da economia, com a inclusão de parcela da população antes marginalizada do mercado consumidor, naturalmente irá trazer maiores gastos energéticos e aumentará a sua intensidade.

A Agência Brasileira de Energia Elétrica ANEEL (2008) corrobora com a hipótese do aumento da intensidade do consumo de energia elétrica no Brasil. Segundo publicação da agência, nos últimos anos o consumo de energia elétrica residencial no Brasil cresceu em um ritmo muito mais acelerado do que o crescimento populacional. Dados do Anuário Estatístico de Energia Elétrica (EPE, 2013) mostram que o consumo de energia residencial no Brasil cresceu 5,1\% entre os anos de 2011 e 2012. Assim, o nível de consumo de energia elétrica residencial no Brasil deve continuar aumentando no futuro devido a dois aspectos associados: aumento das TEC e o processo de envelhecimento populacional. Mas o que buscamos destacar com a análise proposta aqui é que o componente da transição da estrutura etária da população/domicílios não costuma ser levado em consideração nas análises.

É crescente na literatura internacional e nacional a presença de estudos sobre o consumo sob a perspectiva demográfica, comprovando que há vários fatores da dinâmica demográfica que têm grande influência no nível e padrão de consumo de uma população. No caso do Brasil, entretanto, ainda são necessários aprofundamentos para a consolidação da temática população-consumoambiente. $\mathrm{O}$ debate do consumo através da óptica demográfica está se mostrando cada vez mais pertinente para discutir uma "demografia do consumo" de forma mais sistemática e consistente.

A escala de análise, unidades ou métricas de consumo, caracterização demográfica da unidade de pesquisa, fonte de dados e técnicas de análise foram alguns aspectos que necessitam ainda de muitas análises mais aprofundadas para se avaliar suas diversas interfaces. Assim, avançar em estudos que explorem e diversifiquem as abordagens desses termos são de grande pertinência e merecem maiores esforços.

Quanto aos resultados deste artigo, destaca-se que a estrutura etária dos domicílios exerce impacto positivo no consumo de energia elétrica agregado. Mas caberia ainda explorar mais detalhadamente o impacto das mudanças nos arranjos domiciliares, pois se observou importantes diferenciais de consumo per capita de energia elétrica nos domicílios unipessoais e de casais sem filhos. Esses são os arranjos que apresentam as menores quantidades de moradores, que não possuem crianças e que apresentam as maiores rendas per capita, características importantes para o aumento do consumo per capita do domicílio. De forma ainda preliminar, observa-se que os arranjos domiciliares que apresentam maiores níveis de consumo são aqueles que apresentam significativo crescimento em termos proporcionais.

Como limitações dos dados e dos resultados, têm-se os efeitos de renda e da composição familiar no aumento do consumo, além da estrutura etária. Essas variáveis se autocorrelacionam nos processos das transições demográficas, como bem apontam Silva et al. (2012). Desse modo, como sugestão 
para trabalhos futuros, espera-se utilizar técnicas que isolem os efeitos dessas variáveis de confundimento, como foi proposto por Del Guercio (2015), por exemplo. Ou seja, domicílios que apresentam o mesmo nível de renda, mas que possuem idades do chefe e/ou arranjos distintos apresentam também diferentes níveis de consumo?

Além dessa discussão, os resultados da pesquisa ensejam a necessidade de maior atenção às políticas e programas que visem fomentar a economia de energia, pois para haver economia de fato é preciso compensar também os efeitos do envelhecimento populacional futuro e das mudanças nos arranjos domiciliares. Assim, para se chegar a esses ganhos efetivos em termos de economia energética, os novos produtos devem ser cada vez mais eficientes e econômicos e deve haver uma taxa de substituição dos produtos em uma velocidade capaz de superar o processo de envelhecimento, pois não adiantariam ter produtos menos intensivos em uso de energia elétrica nos domicílios brasileiros se estes não estão sendo substituídos.

Os resultados do artigo provocam outros questionamentos que não serão discutidos plenamente nesse trabalho dada sua complexidade, mas que vale a ressalva. Críticas à cultura do consumo e a sua forma mais extremada, o consumismo, e ao caráter individualista cada vez mais presente no modo de consumo em detrimento do compartilhamento de bens e serviços são reflexões que os resultados nos impõem e que devem ser alvo de especial atenção entre os agentes públicos e estar cada vez mais presentes no processo de conscientização da população.

À guisa de conclusão, é necessário reiterar que os resultados dessa pesquisa não negam que haja uma contribuição do volume e a taxa de crescimento populacional nos aspectos ambientais.
Contudo, o que esta pesquisa pretende evidenciar é que há um entendimento malthusiano hegemônico que obscurece a importância de outros fatores demográficos de igual ou maior importância no impacto ao meio ambiente.

Se por um lado os demógrafos já não se preocupam com a necessidade de desmistificar o consenso malthusiano, por outro há um resgate reiterado do "tamanho populacional" como o principal vilão das mudanças ambientais globais por parte não só do senso comum, mas também de outros campos de conhecimento.

Por fim, concluímos que, ao contrário do que se esperaria, reduzir o ritmo de crescimento populacional ou até mesmo apresentar taxas de crescimento populacional negativas poderia acarretar um incremento nos níveis de consumo de energia elétrica domiciliar. Ou seja, menos gente nem sempre é melhor. Tampouco, mais gente é sempre pior. No entanto, é importante ressaltar que isso tende a ser válido até que haja uma estabilização dos níveis de fecundidade e mortalidade da população. Quando isso acontece, não há mais mudanças na estrutura etária da população e possíveis variações nos níveis de consumo da população passam a ser efeitos predominantemente do aumento ou diminuição do número de pessoas, da eficiência energética e/ou até mesmo da variação da composição dessa população por outras características que não a idade. Portanto, inferir que famílias menores são benéficas para o ambiente sem considerar os outros aspectos demográficos, não passa de um reducionismo. 


\section{Referências}

Alves, J. E. D.; Cavenaghi, S. M.; Barros, L. F. W. A família DINC no Brasil: algumas características sócio demográficas. Texto para Discussão. Rio de Janeiro: ENCE/IBGE, 30, p. 1-34, 2010. Disponível em: https://bit.ly/2Xiz9nd

Alves, J. E. D.; Cavenaghi, S. M. Transições urbana e da fecundidade e mudanças dos arranjos familiares no Brasil. Cadernos de Estudos Sociais, 27, 91-114, 2012. Disponível em: http://periodicos.fundaj.gov.br/index.php/CAD

ANEEL - Agência Brasileira de Energia Elétrica. Atlas de energia elétrica do Brasil. ed. - Brasília : Aneel, 2008 Disponível em: $<$ http://www2.aneel.gov.br/arquivos/PDF/ atlas3ed.pdf $>$. Acesso em: out. 2014.

Arriagada, I. Transformaciones familiares y políticas de bienestar en América Latina. In: Arriagada, I. (Org.). Familias y politicas públicas en América Latina: una historia de desencuentros. Santiago: CEPAL, p. 125-149, 2007.

Barros, L. F. W.; Alves, J. E. D.; Cavenaghi, S. M. Novos Arranjos Domiciliares: condições socioeconômicas dos casais de dupla renda e sem filhos (DINC). In: Anais do XVI Encontro Nacional de Estudos Populacionais. Caxambu-MG, 29 de set., 2008.

Carmo, R. L. População e Mudanças Ambientais Globais. Revista Multiciência, 8, 65-87, 2007. Disponível em: https:// bit.ly/2PsiARL

Carvalho, A. A.; Alves, J. E. D. Explorando o consumo das famílias brasileiras e sua interface com o ciclo de vida e gênero. Oikos: Revista Brasileira de Economia Doméstica, 23, 6-29, 2012. Disponível em: https://bit.ly/33ibkzY

Censo Demográfico 1970: características da população e dos domicílios: resultados do universo. In: IBGE. Sidra: sistema IBGE de recuperação automática. Rio de Janeiro, 2015. Disponível em: $<$ https://bit.ly/3etAGhB $>$. Acesso em: mar. 2014.

D'Antona, Á. de O. Do mito malthusiano ao das relações recíprocas - a constituição interdisciplinar do campo de População e Ambiente. Revista Brasileira de Estudos de População, 34(2), 243-270, 2017. doi: 10.20947/S01023098a0006
De Sherbinin, A.; Curran, S. R. Completing the picture: The Challenge of bringing "Consumption" into Population-Enviroment Equation. Population and Enviroment, 26(2), 107-131, 2004. doi: 10.1007/s11111-004-0837-x

Del Guercio, F. M. F. Efeitos da Composição do Domicílio no Consumo de Energia Elétrica: os casos de Lucas do Rio Verde, Santarém e Altamira. Campinas, Dissertação (Mestrado em Demografia) - UNICAMP, 2015.

Druckman, A.; Jackson, T. Household energy consumption in the UK: a highly geographically and socio-economically disaggregated model. Energy Policy, 36(8), 3177-3192, 2008. doi: 10.1016/j.enpol.2008.03.021

EPE - Empresa de Pesquisa Energética. Anuário estatístico de energia elétrica 2013. Rio de Janeiro, 2013. Disponível em: <https://bit.ly/33gzomP>. Acesso em: out. 2014.

Fernandez, J. A. C. G. Ciclo de vida familiar e o projeto de empreendimentos multifamiliares. Florianópolis, Tese (Doutorado em Engenharia Civil) - UFSC, 2006.

Guzman, J. M.; Martine, G.; McGranahan, G.; Schensul, D.; Tacoli, C. Population dynamics and climate change. New York: UNFPA; London: IIED, 2009. Disponível em: https://pubs.iied.org/X00034/

Hogan, D. J. População e Meio Ambiente: a emergência de um novo campo de estudos. In: Hogan, D. J. (Org.). Dinâmica populacional e mudança ambiental: cenários para o desenvolvimento brasileiro. Campinas: NEPO, p. 13-58, 2007. Disponível em: https://bit.ly/30h8b1a

Hogan, D. J. População e mudanças ambientais globais. In: Hogan, D. J; Marandola Jr, E. (Orgs.). População e mudança climática: dimensões humanas das mudanças ambientais globais. Campinas: NEPO; Brasília: UNFPA, p. 11-26. 2009.

Hogan, D. J.; Marandola, E.; Ojima, R. População e ambiente: desafios à sustentabilidade. In: Goldemberg, J. (Org.). Série sustentabilidade. São Paulo: Editora Blucher, 2010.

IBGE - Instituto Brasileiro de Geografia e Estatística. Pesquisa de orçamentos familiares 2008 - 2009: Manual do agente de pesquisa. Rio de Janeiro, 2008. Disponível em: $<$ https://bit.ly/2BNIZXR>. Acesso em: mai. 2014.

IBGE - Instituto Brasileiro de Geografia e Estatística. 
Pesquisa de Orçamentos Familiares 2008/2009. Microdados. Rio de Janeiro, 2009. Disponível em: < https://bit. ly/3kZTpUJ>. Acesso em: fev. 2014.

IBGE - Instituto Brasileiro de Geografia e Estatística. Censo Demográfico 2010. Microdados. Rio de Janeiro, 2010. Disponível em: < https://bit.ly/2IaJmxh > . Acesso em: mar. 2014.

IBGE - Instituto Brasileiro de Geografia e Estatística. Projeção da População do Brasil por sexo e idade: 2000-2060 - Revisão 2013 [Internet]; 2014. Disponível em: http://goo. gl/ANNL9R, Acesso em: março de 2014.

Jiang, L.; Hardee, K. How Do Recent Population Trends Matter to Climate Change? Population Research and Policy Review, 30, 287-312, 2011. doi: 10.1007/s11113010-9189-7

Jiang, L.; O’Neill, B. C. Impacts of demographic trends on us household size and structure. Population and Development Review, 33(3), 567-591, 2007.

Lee, R.; Lee, S. H.; Mason, A. Charting the economic life cycle. NBER Working Paper Series. Cambridge: National Bureau of Economic Research, 12379, p. 1-32, 2006. Disponível em: http://www.nber.org/papers/w12379

Lee, R.; Mason, A. O envelhecimento da população e a economia geracional: principais resultados. Coleção Documentos de projetos. Comissão Econômica para a América Latina e o Caribe - CEPAL, 2010. Disponível em: $<$ https:// bit.ly/2BMGHHk>. Acesso em: set. de 2013.

Leone, E. T.; Maia, A. G.; Balter, P. E. Mudanças na composição das famílias e impactos sobre a redução da pobreza no Brasil. Economia e Sociedade, 19, 59-77, 2010. doi: 10.1590/S0104-06182010000100003

Lesthaeghe, R. The Unfolding Story of the Second Demographic Transition. Population and Development Review, 36(2), 211-251, 2010. doi: 10.2307/25699059

Liddle, B. Consumption-driven environmental impact and age structure change in OECD countries: a cointegration-STIRPAT analysis. Demographic Research, 24(30), 749-770, 2011. doi: 10.4054/DemRes.2011.24.30

Liddle, B.; Lung, S. Age-structure, urbanization, and climate change in developed countries: revisiting STIRPAT for disaggregated population and consumption-related environmental impacts. Population and Environment, 31, 317-343, 2010. doi: 10.1007/s11111-010-0101-5

Lins, F. E. Demanda por energia elétrica residencial urbana no Brasil: uma análise baseada nos micro dados da POF 2002-2003 e 2008-2009. Recife, Tese (Doutorado em Economia) - UFPE, 2010.

Liu, J.; Daily, G. C.; Ehrlich, P. R.; Luck, G. W. Effects of household dynamics on resource consumption and biodiversity. Nature, 421, 530-533, 2003. doi: 10.1038/nature01359

Maia, A. G.; Sakamoto, C. S. Changing family structure and impacts on income distribution: the swift demographic transition in Brazil. In: Population Association of America Annual Meeting, Boston, 1-3 de mai., 2014. Disponível em: https://bit.ly/3i25NkT

Malthus, T. An Essay on the Principle of Population. Londres: J. Johnson, 1798. Disponível em: < http://www.esp. org/books/malthus/population/malthus.pdf $>$. Acesso em: jun. 2014.

Martine, G. Promovendo a demografia da sustentabilidade. In: Martine, G. (Ed.). População e sustentabilidade na era das mudanças climáticas. ABEP: Campinas, p. 11-15, 2012.

Martine, G.; Ojima, R.; Fioravante, E. F. Transporte individual, dinâmica demográfica e meio ambiente. In: Martine, G.; Ojima, R.; Barbieri, A.F.; Carmo, R.L. (Org.). População e sustentabilidade na era das mudanças ambientais globais: contribuições para uma agenda brasileira. Campinas: ABEP, p. 175-186. 2012.

Martine, G; Schensul, D. The Demography of Adaptation to Climate Change. New York: UNFPA; London: IIED; Mexico City: El Colegio de México, p 1-23, 2013.

Martine, G.; Torres, H.; Mello, L. F. de. Cultura do consumo e desenvolvimento econômico na era das mudanças climáticas. In: Martine, G. (Ed.). População e sustentabilidade na era das mudanças climáticas. ABEP: Campinas, p. 19-32, 2012.

Medeiros, M.; Osorio, R. Mudanças nas famílias brasileiras: a composição dos arranjos domiciliares entre 1977 e 1998. Revista Brasileira de Estudos Populacionais, 17, 2000. Disponível em: https://www.rebep.org.br/revista/article/ 
view/356.

Mello, L. F. População, consumo e mudança climática. In: Hogan, D. J; Marandola, E. (Org.). População e mudança climática: dimensões humanas das mudanças ambientais globais. Brasília: UNFPA, p. 109-136. 2009.

Mello, L. F.; Hogan, D. J. População, consumo e meio ambiente. In: Hogan, D. J. (Org.). Dinâmica populacional e mudança ambiental: cenários para o desenvolvimento brasileiro. Campinas: NEPO, p. 59-72, 2007.

Mello, L. F.; Sathler, D. A demografia ambiental e a emergência dos estudos sobre população e consumo. Revista Brasileira de Estudos de População, 32(2), 357-380, 2015. doi: 10.1590/S0102-30982015000000020

Menz, T.; Welsch, H. Population aging and carbon emissions in OECD countries: Accounting for life-cycleand cohort effects. Energy Economics, 34, 842-849, 2012. doi: 10.1016/j.eneco.2011.07.016

Modesto, F. Crescimento populacional e mudanças climáticas: antigas questões em novos contextos. In: D'antona, A. O.; Carmo, R. L. do (Orgs.). Dinâmicas demográficas e ambiente. Campinas: NEPO/Unicamp, p. 175-194, 2011.

Ojima, R. As dimensões demográficas das mudanças climáticas: cenários de mudança do clima e as tendências do crescimento populacional. Revista Brasileira de Estudos Populacionais, 28(2), 389-403, 2011. doi: 10.1590/S010230982011000200009

Ojima, R. Mais quente e mais cheio? Alguns mitos e outras verdades sobre a população e mudanças climáticas no Brasil. In: Martine, G. (Ed.). População e sustentabilidade na era das mudanças climáticas. Campinas: ABEP, p. 57-70, 2012.

Ojima, R.; Diógenes, V. H. D.; Silva, B. L. da. Dynamique démographique et politiques sociales au Brésil. Dilemnes et défis politiques du 'bonus démographique. Problèmes d'Amérique Latine, 93, 31-53, 2014. doi: 10.3917/ pal.093.0031

ONS - Operador Nacional do Sistema Elétrico. Beneficios do horário de verão 2012/2013. Nota à Imprensa. 2013

ONU - Organização das Nações Unidas. World Population Prospects 2019: Highlights. ST/ESA/SER.A/423, 2019. Disponível em: https://population.un.org/wpp/Publications/
Pebley, A. R. Demography and the Environment. Demography, 35(4), 377-389, 1998. doi: 10.2307/3004008

Peña, L. S. Understanding Energy Consumption in Mexico: an Age-Period-Cohort Analysis. In: Anais do XXVII IUSSP International Population Conference. Busan, 26 de aug., 2013.

Satterthwaite, D. The implications of population growth and urbanization for climate change. Environment and Urbanization, 21(2), 545-567, 2009. doi: 10.1177/0956247809344361

Silva, H.; Barbieri, A. F.; Monte-Mór, R. L. Demografia do consumo urbano: um estudo sobre a geração de resíduos sólidos domiciliares no município de Belo Horizonte. Revista Brasileira de Estudos de População, 29(2), 421-449, 2012. doi: 10.1590/S0102-30982012000200012.

Tung, A. Consumption over the lifecycle: an international comparison. In: Lee, R.; Mason, A. Population Aging and the Generational Economy: A Global Perspective. Northampton: Edward Elgar. p. 136-160, 2011.

Martine, G. Population dynamics and policies in the context of global climate change. In: UNFPA; IIED. Population dynamics and climate change. New York, 2009. p. 9-30. Disponível: em: <https://www.unfpa.org/public/publications/pid/4500>. Acesso em: outubro de 2012.

Vanwey, L. K.; D’Antona, A. de O.; Brondízio, E. S.; Morán, E. F. Uso da terra, ciclo de vida da unidade doméstica e ciclo de vida do lote na Amazônia Brasileira. In: Anais do XIV Encontro Nacional de Estudos Populacionais. Caxambú, 20 de set., 2004.

Vollset, S. E.; Goren, E.; Yuan, C.; Cao, J.; Smith, A. E.; Hsiao, T.; Bisignano, C.; Azhar, G. S.; Castro, E.; Chalek, J.; Dolgert, A. J.; Frank, T.; Fukutaki, K.; Hay, S. I.; Lozano, R.; Mokdad, A. H.; Nandakumar, V.; Pierce, M.; Pletcher, M.; Robalik, T.; Steuben, K. M.; Wunrow, H. Y.; Zlavog, B. S.; Murray, C. J. L. Fertility, mortality, migration, and population scenarios for 195 countries and territories from 2017 to 2100: a forecasting analysis for the Global Burden of Disease Study. The Lancet, 396, 1285-1306, 2020. doi: 10.1016/S0140-6736(20)30677-2

Yu E.; Liu J. Environmental impacts of divorce. Proceedings of the National Academy of Sciences of USA - PNAS, 104(51), 20629-20634, 2007. 
Zagheni, E. The leverage of demographic dynamics on carbon dioxide emissions: does age structure matter? Demography, 48, 371-399, 2011. doi: 10.1007/s13524-010-0004-1
Zanon, R. R.; Moretto, A. C.; Rodrigues, R. L. Envelhecimento populacional e mudanças no padrão de consumo e na estrutura produtiva brasileira. Revista Brasileira de Estudos Populacionais, 30, 45-67, 2013. doi: 10.1590/ S0102-30982013000400004. 